\title{
A Study on the Evaluation and Promotion of the Brand Value
}

\author{
Xueli Yang ${ }^{1, a^{*}}$ and Yu Bai ${ }^{2, b}$ \\ ${ }^{12}$ School of Management, Wuhan University of Technology, Wuhan, China \\ a1971996312@qq.com, bbaiyu_whut@163.com \\ *The corresponding author
}

Keywords: Brand; Brand value; Brand value evaluation; Interbrand model; Brand value promotion

\begin{abstract}
As the development of economic, consumers would identify and select a product or service according to the brand, and also they could show their own tastes, values and emotional orientations via the brand. Companies could express enterprise management conception, emotional value relying on the brand. Therefore, the competition between enterprises has gradually from product competition, price competition and advertisement competition to brand competition at present. Brand represents not only the strength, position, business, product or service of an enterprise, also became an intangible assets of business in consumers' mind. At first, this paper introduces the connotation of the brand and the brand value in the first place. Second, a detailed description of the Interbrand method of brand value assessment method. Finally put forward some Suggestions to enhance the brand value. As a special kind of intangible assets, the brand plays a vital role in the process of creating profits. The brand also allows consumers to distinguish between similar products, and reduce their risk of purchase. Brand value evaluation helps enterprises understand their own bands, so that enterprises can take reasonable and effective measures of brand management to enhance their competitiveness, to create greater benefits.
\end{abstract}

\section{Introduction}

On June 22, 2016, the World Brand laboratory issued in 2016 in Beijing (13th) "China 500 most valuable brands" list. On the basis of analysis by the brand strength consumer behavior analysis and financial analysis is obtained based China the most valuable brands in the national team. The State Grid for 305.568 billion yuan topped this year's brand value of brand value. Occupy the top five are Tencent (287.592 billion yuan),Industrial and Commercial Bank of China (274.832billion yuan), Life-insurance company China (253.628 billion yuan) and Haier (221.865 billion yuan).They are China's "national brand", also is a world-class brand.

With China's economic development has entered a new normal, people's living standards are rising, the market, enterprises, consumers and the community's brand awareness is gradually strengthened, enterprises are also more and more attention to the brand building $[1,2]$ Many of the new brand into the public view, consumers have more choices, which will be more conducive to the development of enterprise brand and brand innovation. A good brand can not only allow enterprises to form a clear difference with competitors, given the uniqueness and recognition of enterprises, but also lay the foundation for the development of enterprises. The brand is a symbol of the corporate image, and a good brand will help enhance corporate image in the minds of consumers, to promote sales of enterprise products, which later produced value can also form a fixed brand culture, influence consumers. Brand as the marketability of intangible assets, to increase sales and market share have the effect that cannot be ignored, the famous brand can bring a lot of excess profits for the enterprise, and research its brand value also has an important practical significance. Brand evaluation not only can provide the basis for the merger and acquisition of enterprises, but also enhance the influence of the enterprise, enhance the loyalty of the consumers, and for enterprises to understand the market competition environment [3]. 


\section{The Concept and Method of Brand Value Evaluation}

Brand. The brand of English is Brand, originated in the ancient Norwegian language "Brander". It means "burning" or "branded", refers to the original medieval burger in the cattle, horses, sheep of the brand, to distinguish the different ownership[4].By this way, it is used to mark the private property, such as livestock, which need to be distinguished from others. In the medieval Europe, handicraft craftsmen by using this branding method in their own handicrafts branded on the mark to facilitate customers to identify the product of origin and producer.

As the national brand scientists living in different living conditions, so their understanding of the brand are also different. Now the brand often understood as a trademark, the name of the company, products or services and any other identity can be distinguished from the competitors, advertising company unique market image of the intangible assets. In the Oxford Dictionary, the brand is understood to mean "to prove its ownership, as a mark of quality or other use", that is, to distinguish and prove the quality. The purpose of the brand is to indicate that it can be distinguished from the competitor's product or service. The essence of the brand is quality, no quality brand is zero.

Brand Value. Brand value is an important part of brand management, is also an important sign of the brand that different from other competitive brands. Michael Porter in his "brand competitive advantage" mentioned: the brand's assets mainly in the brand's core values above, or can be said that the core value of the brand is also the essence of the lies [5].

Brand value does not exist independently, and in some respects it includes cost value, relationship value and equity value. At the same time, the brand value is constantly changing that will be affected by various factors, its influencing factors are many, such as advertising, promotion, sponsorship and some other marketing elements. The brand extension will also affect the brand value. Wang Chengrong, a famous scholar of corporate culture and brand strategy, thinks that the value of the brand change process is mainly affected by three factors, that is, the brand's own factors, market competition factors and market demand factors [6].

Brand Value Evaluation. Brand value evaluation refers to a judgment on a brand brings future earnings to the enterprise, which can be used to measure the intangible assets of an enterprise[7]. Brand as a market of intangible assets, how to make a reasonable assessment of its value has become the hot spot in the brand management, which also appeared in a variety of research theory and evaluation methods. With the development of economy, enterprise merger, acquisition and other activities have become increasingly frequent. In these activities, all need to use the brand value evaluation. To be specific, brand value evaluation has the following effect:

First, it can help a strong enterprise mergers or acquisitions of vulnerable enterprises, so that both companies to correct valuation.

Second it is conducive to improving the efficiency of corporate management decision-making. By assessing the value of the corporate brand, it can help the management understand the problems that the enterprise has on the brand, so as to help them make informed decisions about their brand investment and maximize the use of all resources to reduce the waste of investment.

Third, the brand value evaluation can inspire employees and improve the company's reputation. Through the evaluation of brand value, not only can communicate the development of the company's brand, but also can increase the confidence of the internal staff. At the same time, the assessment results can also encourage investors confidence, so as to obtain investors continued investment.

Fourth, brand value evaluation is conducive to the development of joint ventures. With the development of economic globalization, many foreign brands into China. In the past period of time, the Chinese brand awareness is weak, in cooperation with foreign companies, many brands did not make an assessment, to transfer their own brand at a low price to the foreign.

Because the brand value assessment is the future benefit of the brand, therefore, there is a great deal of subjectivity. But this subjectivity does not mean that can be baseless, arbitrary assessment. We must adhere to the principle of fairness and justice, the principle of time and place, the maximum utility principle and the principle of prediction in the assessment process. 


\section{Introduction of Interbrand Method}

The Interbrand company was founded in 1974, is the world's largest integrated brand consulting company, which is the most famous brand evaluation company. The Interbrand method advocated by it is also the world's most widely used assessment method [8]. The "financial world" is also use this method to evaluate value of well-known brands.

The Basic Principle of Interbrand Method. One of the basic assumptions of the Interbrand assessment approach is that brand have value, because in the creation of the brand to pay the cost and branded products compared to non-branded products can get a higher premium[9]. However, the brand value is not just that, but the brand can let its owner in the future to obtain a more stable income. Therefore, the brand value can be brought by the brand's net profit and brand strength multiples these two indicators multiplied by.Fig. 1 is the basic idea of the Interbrand brand value assessment. In general, this approach also includes three aspects of the analysis, that is, brand analysis, market analysis, financial analysis.

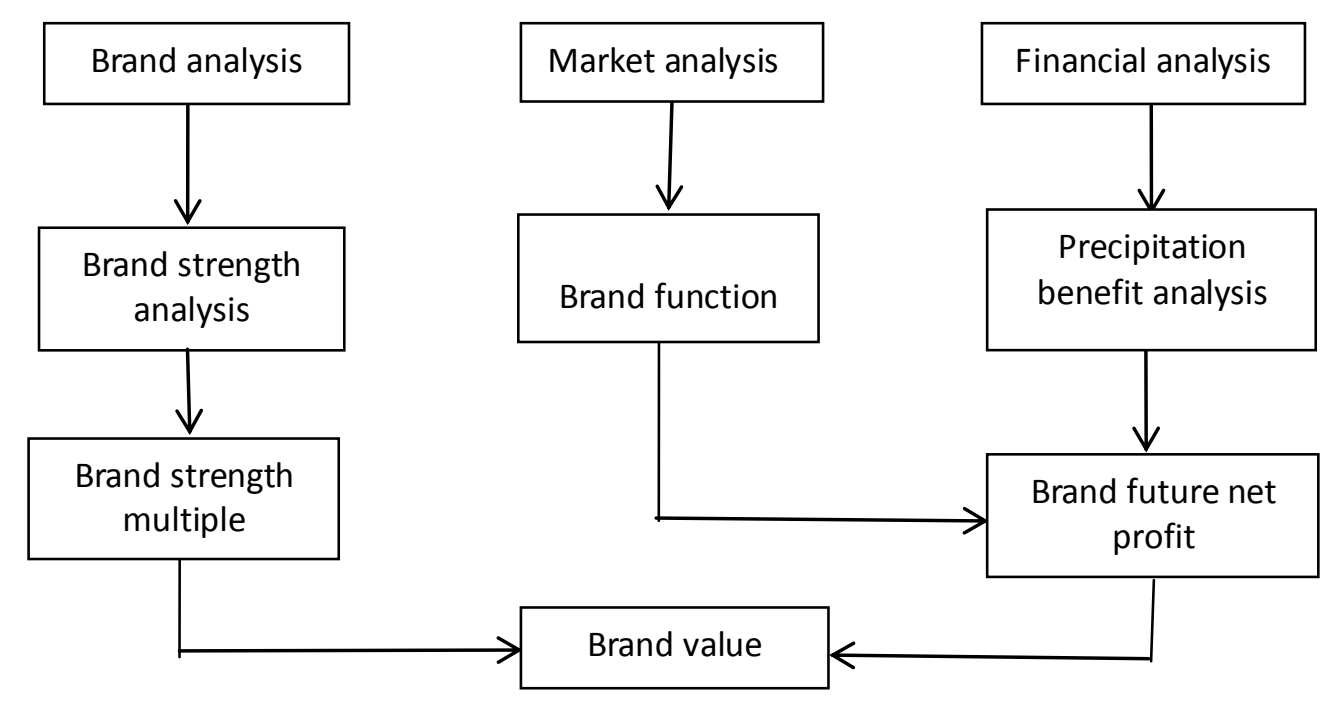

Figure 1. The brand value evaluation basic idea of Interbrand law

The Calculation Formula of Interbrand Method. Firstly, through financial analysis, measure the future income belongs to the intangible assets. Second, by market analysis to determine how much of the intangible assets of future earnings is attributable to the brand. That is the brand's net profit. Third, use the market properties and other factors to determine the brand strength multiplier. Finally, the product of the brand's net profit and brand strength multiples is brand value.

The formula is as follows:

$$
V=P^{*} S
$$

Among them, $\mathrm{V}$ is the brand value; $\mathrm{P}$ is the brand's net profit; $\mathrm{S}$ is the brand strength multiples.

The Specific Calculation Steps of Interbrand Method. The first step: the calculation of the brand's future net profit. First of all, have a financial analysis of the brand, and then get corporate profits value. This aspect data is mainly derived from the company over the years the development of data and open financial statements. Secondly, estimate the total amount of capital that the firm needs to invest to achieve this benefit. Equipment, land, plant, etc., these things in a fixed industry has a recognized average rate of return. Thirdly, estimate the return on non brand factors to the business in the case of normal capital investment. This data is mainly from the industry situation analysis, experts estimate. Finally, the difference from the corporate profit value minus the non-brand factor to the enterprise's return on the return of the difference is the brand to the enterprise to bring the total income. At this time, to remove the normal corporate tax rate is the brand to the enterprise to bring the net profit. 
Table 1 Evaluation of the brand strength of the seven aspects and the highest score value

\begin{tabular}{|l|l|c|}
\hline Indicators & Interpretation & The highest score \\
\hline market nature & $\begin{array}{l}\text { Whether the brand is in a mature and stable market } \\
\text { with high market barriers }\end{array}$ & 10 \\
\hline stability & Whether the brand has more loyal customers & 15 \\
\hline industry status & Whether the brand is in the industry leader & 25 \\
\hline marketing scope & Whether the scope of brand marketing is very broad & 25 \\
\hline brand trend & Whether the brand is related to consumer demand & 10 \\
\hline brand support & Whether the brand has continued to invest & 10 \\
\hline brand protection & Whether the brand is protected by trademark laws & 100 \\
\hline Total & & \\
\hline
\end{tabular}

The second step: the calculation of brand strength multiples. Brand strength multiple $S$ is an expert assessment of the brand strength based on the brand's market nature, stability, industry status, marketing scope, brand trend, brand support and brand protection. Interbrand company to carry on the brand strength of every factor is given the maximum score, the higher the score, the greater the strength, the higher the multiple. Table 1 is the interpretation of the seven factors that Interbrand has evaluated for brand strength and the maximum score. Interbrand company has undergone extensive investigations to determine the general value of the brand strength multiple of the range of between 6 and 20, that is, the value of $S$ range of from 6 to 20 .

In addition, Interbrand company on the basis of massive practice, through a large amount of calculation has developed an s-shaped curve which can make a brand strength score converted to the brand strength of multiple $S$ worth, illustrates the function relationship between the two. Fig. 2shows the brand strength and brand strength score the relationship between the multiple $S$ value.

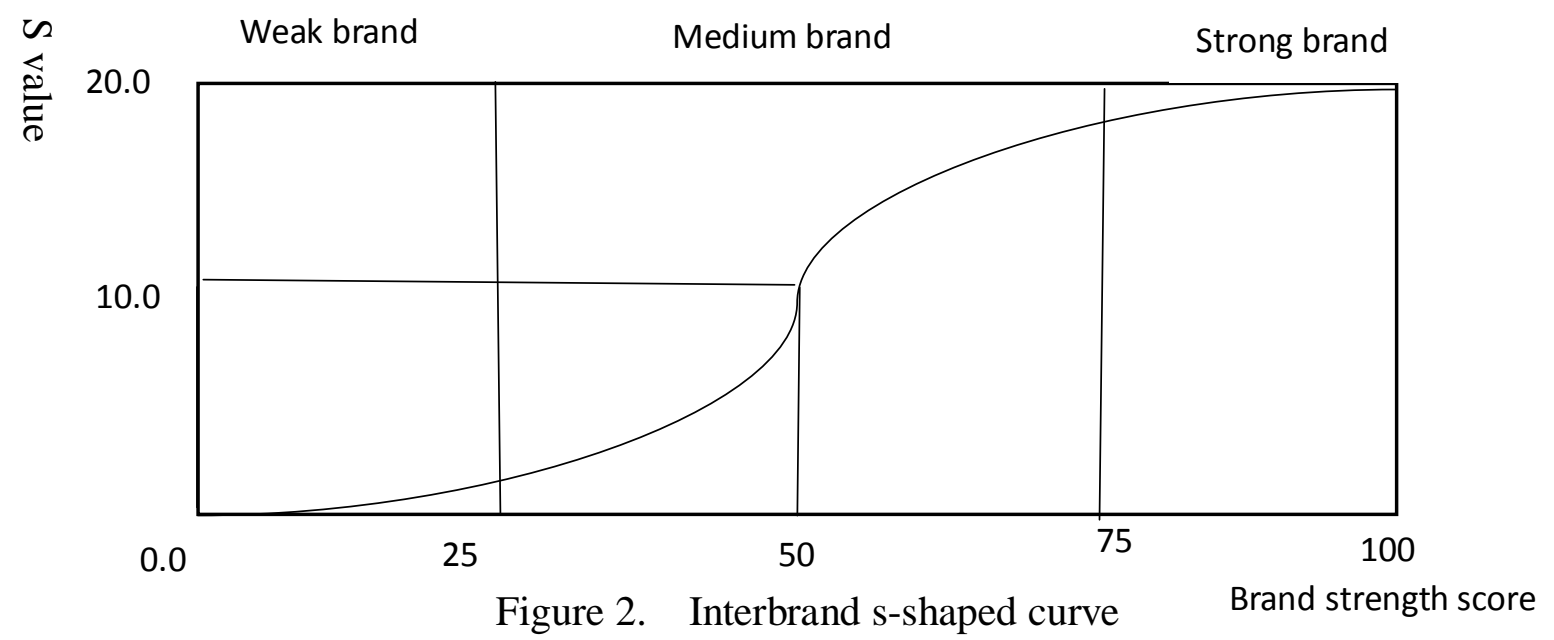

It can be seen from the figure, there is a positive correlation between the brand strength score and the $\mathrm{S}$ value, the brand strength score as the independent variable, the brand strength multiple as the dependent variable, the brand strength multiple with the brand strength score changes. The function of the relationship is as follows:

$$
\begin{aligned}
& Y^{2}=2 X, X \in[0,50] \\
& (Y-20)^{2}=200-2 X, X \in[50,100]
\end{aligned}
$$

Among them, $\mathrm{X}$ is the brand strength score value. $\mathrm{Y}$ is the brand strength multiples, that is, $\mathrm{S}$ value.

The third step: the calculation of brand value. Using the results obtained in the first two steps, the 
brand to bring the net profit and brand strength multiples is the brand value.

\section{Suggestions on Brand Value Promotion}

Increase Brand Connotation, Build Brand Culture. Brand is the symbol of enterprise products. Brand connotation is the soul of the product. Enterprise brand innovation can be from the brand core concept innovation, the customer value innovation and brand external image from three aspects.

Innovative Marketing Communications. Under the condition of informatization developed market, the effective marketing communication to the brand is also an important approach to enhance the brand value. Enterprises need to through effective means to transfer brand information to consumers, so that consumers recognize the brand transfer function and value, also need to form fit in emotional with consumers, to achieve a deeper level of innovation. For example, integrated marketing communication.

Actively Assume Social Responsibility. By the social nature of the enterprise can be seen, the enterprise is born with social responsibility to bear the property. With the development of economy and the increasing social responsibility of enterprises, the commitment of corporate social responsibility is becoming more and more important for the realization of enterprise economic benefits and the promotion of brand value. The corporate strategy should be linked to the social responsibility of the enterprise. Abide by the relevant laws and regulations. Follow the basic social morality. Establish good public relations with the outside world, to carry out practical social welfare activities, and establish a positive social responsibility of the enterprise image.

\section{Conclusions}

In the rapid development of the economy today, many brands live in the market. Consumers use brand to recognition and select products or services, by brand to show their own tastes, values and emotional orientation. Enterprises rely on the brand to convey business philosophy, emotional value. Business competition has gradually from product competition, price competition to marketing competition, brand competition [10].Brand to a certain extent, represents the strength of a business, status. The brand value evaluation is becoming more and more attention. The value of the brand is the embodiment of competitive advantage, on the one hand, the high-quality of the brand is conducive to enterprises to obtain the market, on the other hand, the high-quality brand is also conducive to reducing the risk of consumers, to safeguard the rights and interests of consumers.

\section{References}

[1] S.L. Pang: Brand Management. (Tsinghua University Press, China 2011), p. 190-194.(In Chinese)

[2] R.R. Li: Market Modernization, (2014) No.19, p.102. (In Chinese)

[3] Q.G. Zhao and H.J. Gu: Friends of Accounting, (2011).No.2, p.18-20. (In Chinese)

[4] Y.C. Xie: Study on the evaluation of brand value based on Interbrand model (Ph. MS., Jinan University, China 2015), p. 16. (In Chinese)

[5] C.P. Lin and C.M. Chuang: International Marketing Review, Vol. 33(2016) No. 6. p. 758 780.

[6] Y.P. Gong and F.L. Chen: Seeker, (2014) No.3, p.24-30. (In Chinese)

[7] L.DUGULEANĂ et al: Bulletin of the Transilvania University of Braşov Series, Vol. 7(2014) No.1, p41-52.

[8] J.J. Tang and Q.X. Yang: China Business Update, (2015), No.21, p.82. (In Chinese) 
[9] J. Sun: International English Education Research, Vol. 35 (2015) No.5, p.98-100.

[10] W.J. Lee, A. O’Cass and P. Sok: European Journal of Marketing, Vol. 51 (2017) No.1 p.177-199. 